\title{
Understanding the Mechanisms Involved in Shape Memory Starch: Macromolecular Orientation, Stress Recovery and Molecular Mobility
}

\author{
Cyril Véchambre, ${ }^{+}$Alain Buléon, ${ }^{\dagger}$ Laurent Chaunier, ${ }^{\dagger}$ Catherine Gauthier, ${ }^{\dagger}$ and Denis Lourdin ${ }^{+, *}$ \\ ${ }^{\dagger}$ INRA, UR1268, Unité Biopolymères Interactions et Assemblages, 44300 Nantes, France \\ ${ }^{\ddagger}$ Insa-Lyon, MATEIS CNRS UMR 5510, Université de Lyon, 69621 Villeurbanne, France
}

\begin{abstract}
The effect of a deformation near and above the glass transition on macromolecular orientation, residual stress, and molecular mobility was investigated on amorphous stimuli-responsive starch. The recovery stress, linked to the residual stress in the temporary shape, evolves linearly with the macromolecular orientation. Increasing the deformation temperature decreases the residual stress and the macromolecular orientation. This also leads to a higher glass transition temperature induced by a decrease in molecular mobility. The local structures potentially involved in orientation and stress recovery and their behavior during deformation at different temperatures are discussed.
\end{abstract}

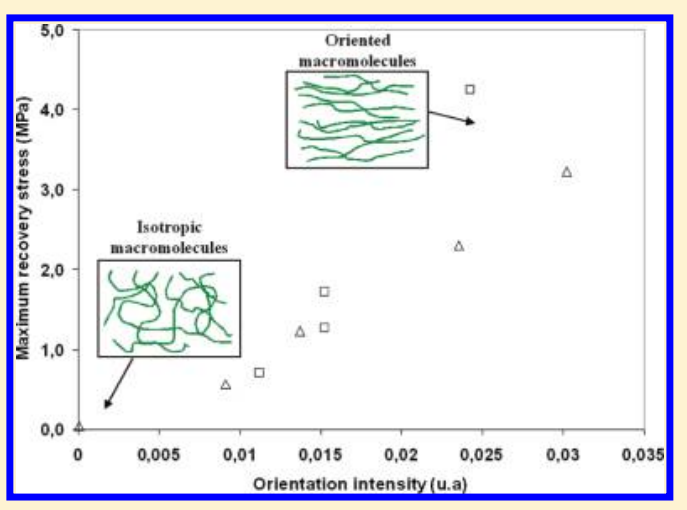

\section{INTRODUCTION}

Shape memory polymers (SMP) are stimuli-responsive materials that recover their initial shape (permanent shape) after being deformed into a temporary one when exposed to a stimulus such as heat, humidity, $\mathrm{pH}$, or electric or magnetic field. ${ }^{1}$ Among the numerous and high-value applications of SMP, their potential use in the (bio)medical field, mainly for minimally invasive surgical devices, has been extensively studied. ${ }^{2}$ For this specific application, the polymer must be biocompatible and resorbable. The ability of a polymer to respond to a stimulus results from both its intrinsic macromolecular structure and specific morphology, which can be obtained during its processing by applying a wellcontrolled thermomechanical pathway. This type of morphology usually consists of two types of domains with different molecular mobilities. The first one, with a high transition temperature, acts as a network and is responsible for the permanent shape. In the second one, more flexible segments frozen below a transition temperature $\left(T_{\text {trans }}\right)$ become flexible above this switching temperature, which may be the glass transition temperature $\left(T_{\mathrm{g}}\right)$. Heating the sample in its temporary shape above this switching temperature causes the material to recover its permanent shape. ${ }^{3}$ Different groups of shape memory polymers have been identified. ${ }^{4}$ In the case of thermoplastic SMP, the network consists of physical cross-links such as entanglements, and flexible domains, referred to as amorphous chains. ${ }^{4}$

Starch is the major energy reserve of a wide variety of higher plants such as cereals, legumes and tubers. As an abundant and inexpensive renewable resource, it is increasingly processed to obtain biodegradable materials. Starch structure and processing have been extensively studied, as have the properties of the resulting thermoplastic material. ${ }^{5-7}$ It has been recently demonstrated that thermoplastic starch can present a shape memory triggered by its glass transition temperature. Since it is also plasticized by water, starch can be used to produce both humidity and temperature responsive materials. ${ }^{8-10}$ The shape memory performances of thermoplastic starch are high and comparable to those of synthetic SMP. Indeed, the shape fixity is higher than $95 \%$ and the shape recovery reaches more than $90 \%$ for stretching up to $200 \%{ }^{9}$ Starch is also biocompatible and resorbable, which makes it a potential candidate for application in the (bio)medical field. ${ }^{11}$ In thermoplastic starch, the shape memory effect is predominantly due to the amorphous state, recrystallization, even partial, reducing its efficiency. ${ }^{9}$ At the macroscopic scale, the shape memory effect is related to stored stress in the temporary shape and leads to specific birefringence. ${ }^{8}$ This stored stress, referred to as "residual stress", results from the applied thermomechanical process and can be linked to different factors such as, for example, the presence of thermal gradients or chain orientations. ${ }^{12,13}$ The measurement of residual stress can be achieved by thermomechanical trials known as "recovery stress tests". ${ }^{14}$ It has been demonstrated that shape recovery corresponds to the relaxation of this residual stress and leads to a loss of birefringence. The macromolecular orientation revealed in the temporary shape disappears during shape recovery above $T_{\mathrm{g} .}{ }^{15}$

In our knowledge, besides a polymer based on bile acid ${ }^{16}$ and a poly(lactic acid) (PLA) ${ }^{17}$ which can be produced by fermentation, starch is the only natural polymer having shape memory properties. Therefore, it is necessary to elucidate the mechanisms

\section{Received: September 5, 2011 \\ Revised: October 28, 2011 \\ Published: November 10, 2011}




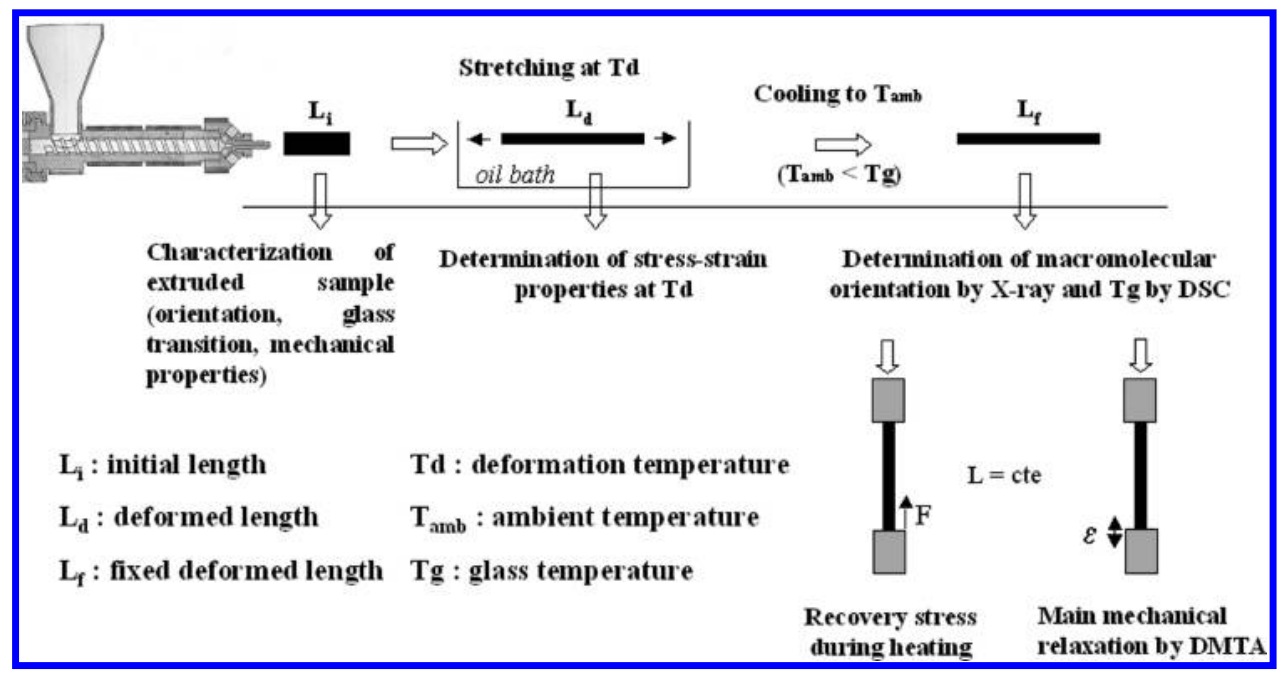

Figure 1. Schematic representation of the thermomechanical history applied to the different samples and the way they were characterized.

involved in shape memory of such polymers and also the impact of processing on their performances. Although some specific morphologies and mechanisms responsible for the starch shape memory effect have been proposed, ${ }^{15}$ the effect of the deformation, applied to produce the temporary shape, on molecular mobility has never been studied in starch-based materials. Some studies ${ }^{18,19}$ have reported that a deformation above $T_{\mathrm{g}}$ on amorphous synthetic polymers induces a change in the molecular mobility and, in consequence, has an impact on the glass transition of the material considered.

The purpose of the present paper is to investigate the effect of the deformation temperature on (i) the macromolecular orientation and the recovery stress and (ii) the glass transition and mechanical relaxations associated with chain mobility.

\section{EXPERIMENTAL SECTION}

Raw Material. Native potato starch was obtained from Roquette (Lestrem, France). The amylose/amylopectin ratio was 23/77.

Extrusion. Starch was mixed with water prior to extrusion. The moisture content was set at $27 \% \mathrm{wb}$ (wet basis). The mixture was extruded under the usual conditions $\left(T_{d i e}, 120^{\circ} \mathrm{C}\right.$; die pressure, $170 \mathrm{bar}$; torque,: $20 \mathrm{~N} . \mathrm{m}$; SME, $422 \mathrm{~J} \cdot \mathrm{g}^{-1}$ ) using a SCAMIA single-screw device (Rheoscam Type 20.11d, Crosne, France). Special care was taken to set a low screw speed $(20 \mathrm{rpm})$ in order to avoid the macromolecular orientation due to flow at the extruder outlet. Samples were extruded as cylinders (cylindrical die: o.d. $1 \mathrm{~mm}$ ). After flowing through the die and storage in a closed vessel containing a saturated sodium bromide solution $\left(\mathrm{NaBr}, \mathrm{RH}=59 \%\right.$ at $\left.20^{\circ} \mathrm{C}\right)$ for 15 days to reach a stable water content, the cylindrical samples had a diameter of approximately $2 \mathrm{~mm}$. Their water content was $13 \% \mathrm{wb}$.

Water Content and Glass Transition Temperature. The water content was measured by thermogravimetry using a TGA2050 (TA Instruments, DE). It was evaluated from the weight loss of a sample weighing approximately $10 \mathrm{mg}$, maintained at $130^{\circ} \mathrm{C}$ for $120 \mathrm{~min}$. The glass transition temperature was determined by differential scanning calorimetry (DSC) using a T.A. Q100 instrument (T.A. Instruments, New Castle, DE). The system was calibrated with indium. Experiments were carried out on samples weighing approximately $10 \mathrm{mg}$ in sealed aluminum cells, to prevent loss of water during analysis. Two successive scans were run at $3{ }^{\circ} \mathrm{C} \cdot \mathrm{min}^{-1}$ between 20 and $120^{\circ} \mathrm{C}$, separated by a cooling stage. The glass transition temperature was determined at the midpoint of the calorific capacity change during the second scan.
Wide-Angle X-ray Scattering (WAXS). Two-dimensional WAXS diagrams were recorded using a Bruker D8 X-ray diffractometer (Madison, WI) equipped with a two-dimensional GADDS detector. The $\mathrm{X}$-ray radiation, $\mathrm{Cu} \mathrm{K} \alpha_{1}(\lambda=0.15405 \mathrm{~nm})$, produced in a sealed tube at $40 \mathrm{kV}$ and $40 \mathrm{~mA}$, was selected and parallelized using a Gobël mirror parallel optics system and collimated to produce a $500 \mu \mathrm{m}$ beam diameter. WAXS diagrams were recorded in the transmission mode with specimens lying with their length parallel to the vertical axis of the detector. Orientation was determined by azimuthal integration between $0.680\left(2 \theta=13^{\circ}\right)$ and $0.386 \mathrm{~nm}\left(2 \theta=23^{\circ}\right)$ corresponding to the amorphous scattering band. During the recording time (20 min) dehydration was evaluated at less than $0.5 \%$ and had no effect on the results.

Mechanical Properties. Stress-strain curves were acquired on an MTS Synergie 100 apparatus equipped with a $100 \mathrm{~N}$ load cell. In order to control the temperature, it was equipped with a device specifically designed in the laboratory that made it possible to immerse the sample in an oil bath at the desired temperature. The deformation rate was set at $100 \% \cdot \min ^{-1}$. Test time was approximately $1 \mathrm{~min}$. The unavoidable dehydration of the sample was evaluated at approximately $0.5 \%$ for 80 and $90^{\circ} \mathrm{C}$, and at $1 \%$ for 100 and $115^{\circ} \mathrm{C}$. Mechanical trials were carried out on $2 \mathrm{~mm}$ diameter samples. All experiments were repeated five times.

Dynamical Mechanical Thermal Analysis. A DMTA MKIV apparatus (Rheometrics Scientific, Piscataway, New Jersey, USA) was used in the tensile mode at a frequency of $1 \mathrm{~Hz}$ with a deformation amplitude of $0.01 \%$. This value is in the range of linear viscoelasticity, and any deviation from this domain during heating was discarded and assumed to be the same for all samples tested. The heating rate was set at $3^{\circ} \mathrm{C} \cdot \mathrm{min}^{-1}$. Prior to DMTA trials, cylindrical samples were coated with a silicone-based hydrophobic grease to limit dehydration during experiments above room temperature. The dehydration was approximately $0.3 \%$ at $60{ }^{\circ} \mathrm{C}, 0.9 \%$ at $80{ }^{\circ} \mathrm{C}, 1.8 \%$ at $100{ }^{\circ} \mathrm{C}$ and $3 \%$ at $120^{\circ} \mathrm{C}$. It has been previously shown that such a thin coating of grease has no effect on the thermomechanical properties. ${ }^{20}$

Recovery Stress Analysis. The recovery stress analysis was performed on the DMTA MKIV apparatus (Rheometrics Scientific, Piscataway, New Jersey, USA) using the "stress relaxation test" mode. Extruded cylinders deformed at various temperatures were clamped with the tensile mode tools and could not recover their original shape during the test. The length was set and maintained at $10 \mathrm{~mm}$. Cylinders were coated with a silicone-based hydrophobic grease to limit dehydration during experiments above room temperature. The heating rate was set at $8{ }^{\circ} \mathrm{C} \cdot \mathrm{min}^{-1}$.

Figure 1 summarizes the thermomechanical stages applied to samples (extrusion, deformation and cooling), the characterization of their 


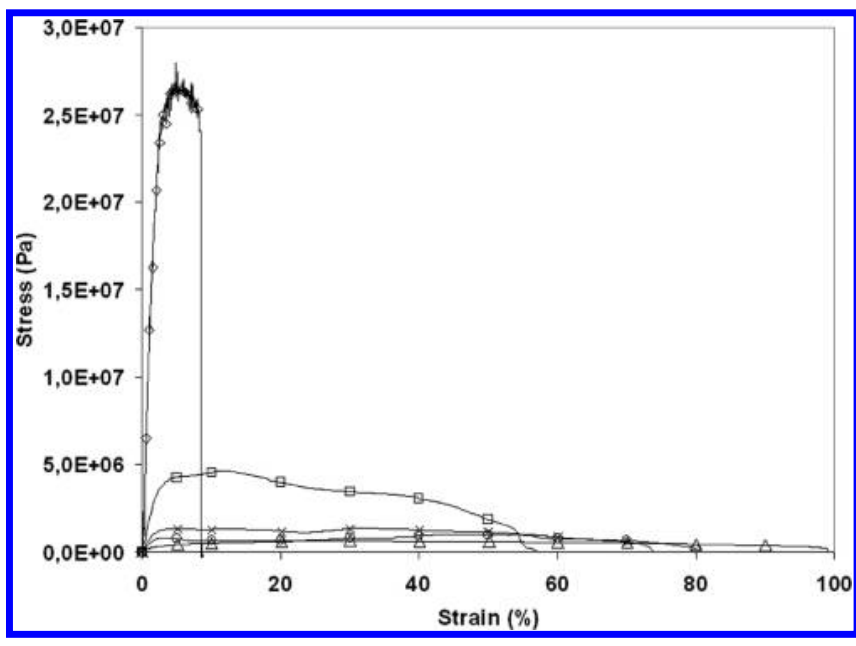

Figure 2. Stress-strain curves for starch material obtained at different temperatures. Key: $(\diamond) 25^{\circ} \mathrm{C}$; $(\square) 80^{\circ} \mathrm{C}$; $(\times) 90^{\circ} \mathrm{C}$; $(\bigcirc) 100{ }^{\circ} \mathrm{C}$; $(\Delta)$ $115^{\circ} \mathrm{C}$.

Table 1. Values of the Young Modulus (E), Tensile Strength at Rupture $\left(\sigma_{\mathrm{r}}\right)$, and Elongation at Rupture $\left(\varepsilon_{\mathrm{r}}\right)$ as a Function of the Temperature

\begin{tabular}{cccr} 
temperature of deformation, ${ }^{\circ} \mathrm{C}$ & \multicolumn{1}{c}{$E, \mathrm{MPa}$} & $\sigma_{\mathrm{R}} \mathrm{MPa}$ & $\varepsilon_{\mathrm{R}} \%$ \\
25 & $1030 \pm 40$ & $27.00 \pm 0.10$ & $9 \pm 1$ \\
80 & $197 \pm 25$ & $1.70 \pm 0.04$ & $52 \pm 2$ \\
90 & $77 \pm 10$ & $0.92 \pm 0.04$ & $68 \pm 5$ \\
100 & $42 \pm 7$ & $0.41 \pm 0.04$ & $80 \pm 6$ \\
115 & $25 \pm 4$ & $0.29 \pm 0.02$ & $85 \pm 9$ \\
\hline
\end{tabular}

properties (stress-strain, $T_{\mathrm{g}}$, orientation, recovery stress and mechanical relaxation) and the variables involved.

\section{RESULTS AND DISCUSSION}

After extrusion, samples stored at $\mathrm{RH}=59 \%$ presented a stable water content at $13 \% \mathrm{wb}$, and their glass transition temperature was $75^{\circ} \mathrm{C}$.

Mechanical trials until rupture performed at different temperatures led to the stress-strain curves shown in Figure 2. The key data are summarized in Table 1 . The curve obtained at $25^{\circ} \mathrm{C}$, below the glass transition, which shows a beginning of ductility, is characteristic of a thermoplastic material deformed in the vitreous state. The Young modulus is approximately $1 \mathrm{GPa}$ and the tensile strength approximately $27 \mathrm{MPa}$. The elongation at rupture is measured at $8 \%$. These data correspond to the classic mechanical behavior of vitreous starch previously reported in the literature. ${ }^{20}$ As the temperature increases from 80 to $115^{\circ} \mathrm{C}$, the Young modulus decreases from 200 to $25 \mathrm{MPa}$ and the tensile strength from 1.7 to $0.3 \mathrm{MPa}$. At the same time, elongation increases from 52 to $85 \%$. The mechanical behavior observed at $80{ }^{\circ} \mathrm{C}$ is different from that at 90,100 , and $115{ }^{\circ} \mathrm{C}$. The curve obtained at $80{ }^{\circ} \mathrm{C}$ is characteristic of a polymer deformed at $T_{\mathrm{g}}$. The curves obtained above $T_{\mathrm{g}}\left(90,100\right.$, and $\left.115^{\circ} \mathrm{C}\right)$ and that exhibit no significant strain hardening show that the main phenomena that occur at high strain can be attributed to disentanglement phenomena. VanSoest et al. ${ }^{21}$ observed that at high strain, the behavior of starch plasticized with $27 \%$ glycerol and $14 \%$ water is typical of rubber with strain hardening. In our case, the nonstrain

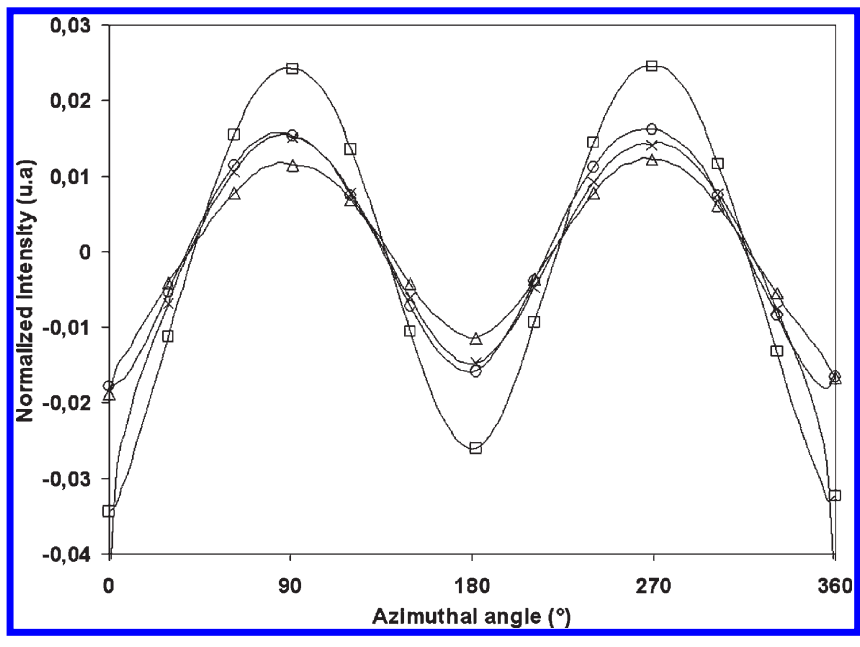

Figure 3. Orientation diagrams from WAXS spectra. Stretched at ( $\square$ ) $80,(\times) 90,(\bigcirc) 100$, and $(\Delta) 115^{\circ} \mathrm{C}$. Final deformation set at $50 \%$.

hardening observed might also be due to a partial dehydration leading to breakage of some intermolecular bonds.

A common level of stretching before the rupture was chosen from the stress-strain curves to prepare "deformed samples" at four temperatures: $80,90,100$, and $115^{\circ} \mathrm{C}$, with a deformation ratio of $50 \%$. After deformation, samples were cooled at ambient temperature while maintaining the deformation. If the cooling rate is high enough, it is assumed that the orientation associated with entropic elasticity is frozen in the sample. These samples will be referred to as "deformed samples" and the deformation temperature as " $T_{\mathrm{d}}$ " in the next.

(i). Macromolecular Orientation and Recovery Stress. Macromolecular orientation was characterized by wide-angle X-ray scattering, WAXS, for the different deformed samples. ${ }^{22}$ WAXS diagrams present no clear diffraction peak, but only a broad amorphous scattering band for all samples. The scattering maximum corresponds to a repeated distance of approximately $0.5 \mathrm{~nm}$, which is usually considered to arise from the van der Waals contacts of nonbonded atoms (VDW spacings). ${ }^{23}$ Figure 3 represents the azimuthal integration of the scattering intensity between 0.680 and $0.386 \mathrm{~nm}$ for samples deformed at $80,90,100$, and $115^{\circ} \mathrm{C}$. It exhibits periodic changes with the azimuthal angle, which reveals the presence of an orientation. A maximum scattering intensity is observed at $90^{\circ}$ and $270^{\circ}$ for all samples, which shows that the orientation is parallel to the stretching direction. Scattering intensity at this maximum depends on the deformation temperature. It decreases from 0.0242 to 0.0114 when the $T_{\mathrm{d}}$ increases from 80 to $115{ }^{\circ} \mathrm{C}$ (Figure 3). This decrease of orientation with increasing deformation temperatures has already been observed and was attributed to the greater ability of chains to rapidly reorganize at higher temperatures between $T_{\mathrm{d}}$ and $T_{\mathrm{g}}$ at the end of the stretching. ${ }^{15}$ This is not the case for semicrystalline polymers whose the structure is stabilized by crystalline domains. ${ }^{24}$ For the nondeformed sample, a weak residual orientation is observed. It is induced by melt shearing during extrusion and is conserved by cooling and dehydration after flowing through the die (data not shown).

Residual stress was also investigated thanks to recovery stress measurements. Recovery stress is a method designed for shape memory materials to determine the internal stress stored in the material during the deformation step. ${ }^{25}$ Figure 4 represents the 


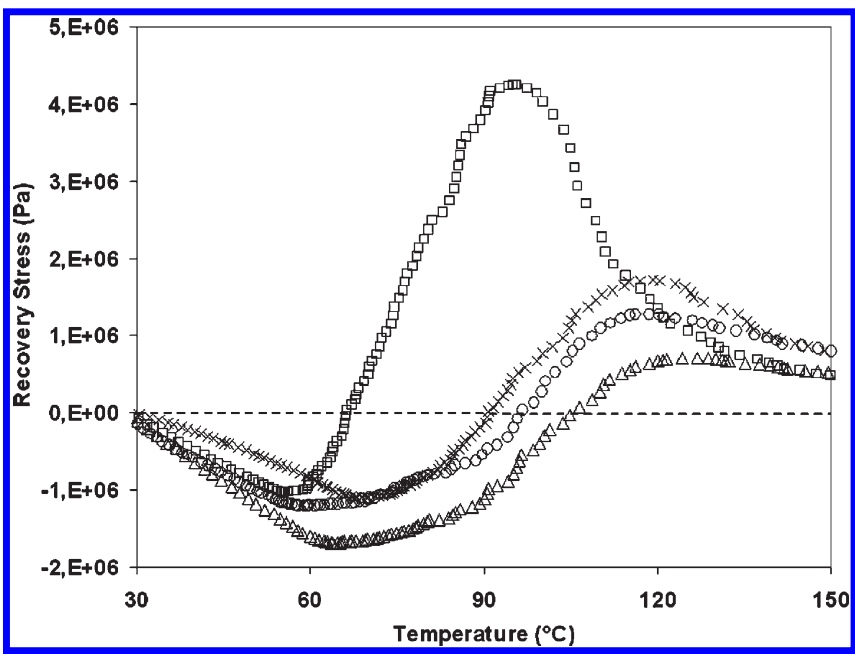

Figure 4. Evolution of the recovery stress for samples stretched at $(\square)$ $80,(\times) 90,(O) 100$, and $(\Delta) 115{ }^{\circ} \mathrm{C}$. Final deformation set at $50 \%$ heating rate: $8{ }^{\circ} \mathrm{C} \cdot \mathrm{min}^{-1}$.

evolution of the recovery stress measured at a heating rate of $8^{\circ} \mathrm{C} \cdot \mathrm{min}^{-1}$ on the four deformed samples. The shape of the curves is similar for all samples. Stress first decreases due to thermal dilatation when the sample is heated, and reaches a minimum at a temperature depending on the $T_{\mathrm{d}}$. It ranges from 55 to $70^{\circ} \mathrm{C}$ for samples deformed at 80 and $115^{\circ} \mathrm{C}$, respectively. In the second part of the curves, which begins at $60{ }^{\circ} \mathrm{C}$ for the sample deformed at $80{ }^{\circ} \mathrm{C}$, the stress increases almost linearly with temperature in the glass transition domain and correspond to the recovery stress. The maximum recovery stress is reached at a temperature that varies from 95 to $125^{\circ} \mathrm{C}$ when the $T_{\mathrm{d}}$ increases from 80 to $115^{\circ} \mathrm{C}$, respectively.

The maximum recovery stress is much higher, $4.2 \mathrm{MPa}$, for the sample deformed at $80^{\circ} \mathrm{C}$ than for the others, and decreases with the $T_{\mathrm{d}}$ down to $0.7 \mathrm{MPa}$ for the sample deformed at $115^{\circ} \mathrm{C}$. Wong and Venkatraman ${ }^{26}$ showed a similar behavior on semicrystalline PLA films, but with higher recovery stress values that varied between 5 and $30 \mathrm{MPa}$. At higher temperatures $\left(>125^{\circ} \mathrm{C}\right)$, the stress decreases to a value close to zero after reaching the maximum value, which could be explained by stress relaxation. After the recovery stress measurement, the measured macromolecular orientation was at a level comparable to that obtained after the initial deformation. This level of orientation, even after relaxation could originate from a stress induced crystallization due to annealing as encountered for synthetic polymers. ${ }^{27}$ While no clear diffraction peaks were observed by WAXS, this hypothesis cannot be discarded.

For the nondeformed sample, very little stress is developed $(35 \mathrm{kPa})$. This confirms that extruded samples retain a very small amount of residual stress that is fixed when cooled at the extruder outlet.

The present multiscale approach reveals a decrease in both macromolecular orientation and recovery stress when the deformation temperature increases. Both phenomena are associated with the decrease in entropy linked to the conformational changes induced by deformation. Figure 5 shows the evolution of the maximum recovery stress with orientation intensity.

The maximum recovery stress increases almost linearly with increasing orientation, regardless of the thermomechanical history. This means that the driving force for the starch shape

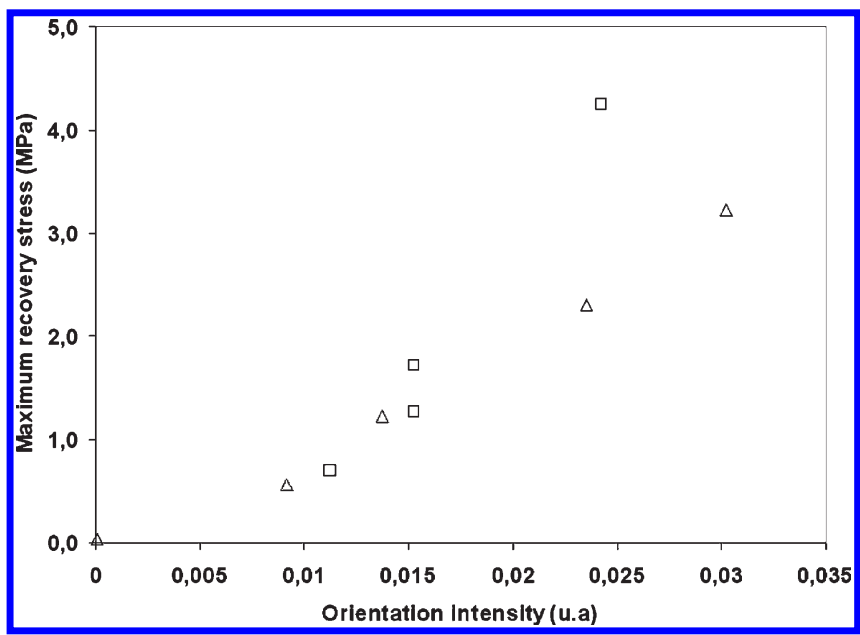

Figure 5. Evolution of the maximum recovery stress as a function of the orientation intensity for different deformation temperatures $(\square$, values presented in the publication; $\Delta$, values obtained under similar conditions but orientation diagrams not presented in the present publication).

memory is the behavior of oriented amorphous segments that act as "entropic springs" above $T_{\mathrm{g}}$.

Thus, optimization of the maximum recovery stress of shape memory starch materials could be done by controlling macromolecular orientation with deformation temperatures.

(ii). Glass Transition and Mechanical Relaxations Associated with Chain Mobility. We demonstrate that residual stress induced by a deformation is linked to the orientation of polymer chains. Different authors reported that a deformation above the glass transition may induce a modification in the molecular mobility. ${ }^{18,19}$ Shelby et al. ${ }^{18}$ observed a decrease of the molecular mobility for a polycarbonate (PC) when stretched above its glass transition, and showed that it was induced by an increasing orientation. Diaz-Calleja et al. ${ }^{19}$ reported an increase of the molecular mobility with increasing stretching for an aromatic polyester. In the case of cross-linked elastomers (SBR, NBR), Munch et al. ${ }^{28}$ did not observe any impact of the deformation above $T_{\mathrm{g}}$ on chain mobility. These different results show that the effect of a deformation above $T_{\mathrm{g}}$ on molecular mobility is not intrinsic to the amorphous state but seems to depend on the molecular structure of the polymer as well.

In order to more closely assess the relationships between molecular mobility and residual stress, DMTA was used to study mechanical relaxation associated with molecular mobility. Parts a and $\mathrm{b}$ of Figure 6 show the evolution of the storage modulus, $E^{\prime}$, and the phase angle, $\tan \delta$, for samples deformed at various $T_{\mathrm{d}}$. Changes in $E^{\prime}$ as a function of the temperature follow the same trend for all samples and involve two steps: a first slow decrease of $E^{\prime}$ between 40 and $80{ }^{\circ} \mathrm{C}$, followed by a faster one starting at $85-115{ }^{\circ} \mathrm{C}$ corresponding to the glassy/rubbery transition and leading to the $\alpha$ relaxation. For the nondeformed sample, the second phenomenon starts at approximately $85{ }^{\circ} \mathrm{C}$, which roughly corresponds to the glass transition temperature determined by DSC. For the deformed samples, this temperature increases from 98 to $115{ }^{\circ} \mathrm{C}$ when $T_{\mathrm{d}}$ varies from 80 to $115{ }^{\circ} \mathrm{C}$. This could be due to a loss of molecular mobility induced during the deformation of the specimen.

In Figure $6 \mathrm{~b}$, the temperature corresponding to the maximum of the loss factor, attributed to the $\alpha$ relaxation, shifts from $115^{\circ} \mathrm{C}$ for the nondeformed sample, to $130^{\circ} \mathrm{C}$ for the sample 


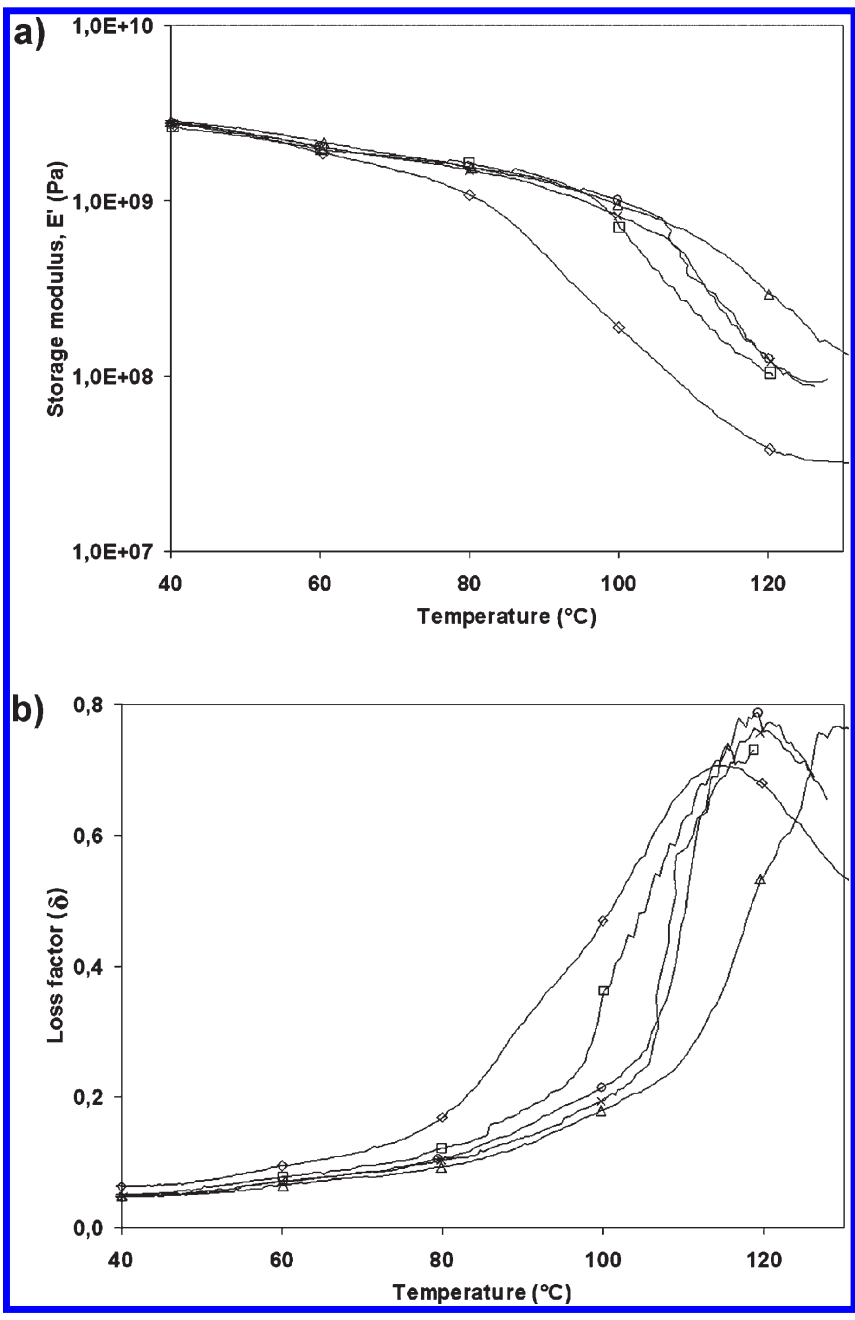

Figure 6. Evolution of the storage modulus (a) and the loss factor (b) for $(\diamond)$ nonstretched and stretched at $(\square) 80,(\times) 90,(\bigcirc) 100$, and $(\Delta)$ $115^{\circ} \mathrm{C}$. Final deformation set at $50 \%$, for a frequency of $1 \mathrm{~Hz}$ and a heating rate of $3{ }^{\circ} \mathrm{C} / \mathrm{min}$.

deformed at $115^{\circ} \mathrm{C}$. As for the storage modulus, such behavior can be explained by a decrease of the molecular mobility induced by the deformation. In contrast, the amplitude of the maximum of $\tan \delta$ is not affected by the deformation temperature. This confirms that no crystallization has occurred.

A shoulder is visible for the nondeformed sample and, to a lesser extent, for samples deformed at 80 and $90^{\circ} \mathrm{C}$. It shifts from $90{ }^{\circ} \mathrm{C}$ for the nondeformed sample, to $110{ }^{\circ} \mathrm{C}$ for the sample deformed at $90{ }^{\circ} \mathrm{C}$, but its origin remains uncertain. These measurements were completed by DSC analysis, which is a key technique used to study the glass transition associated with molecular mobility. The use of sealed pans combined with very small empty volumes makes it possible to maintain the water content of the sample constant during the measurement.

Figure $7 \mathrm{a}$ shows a thermogram characteristic of a nondeformed thermoplastic starch. In the first scan, an endothermic peak at about $50^{\circ} \mathrm{C}$ is observed, characteristic of physical aging. ${ }^{29}$ At higher temperatures, the midpoint of the change in the calorific capacity at approximately $75^{\circ} \mathrm{C}$ in the first and second scan was attributed to the glass transition.

Figure $7 \mathrm{~b}$ shows the corresponding thermograms for the samples deformed at 90 and $115^{\circ} \mathrm{C}$. For both samples, the glass

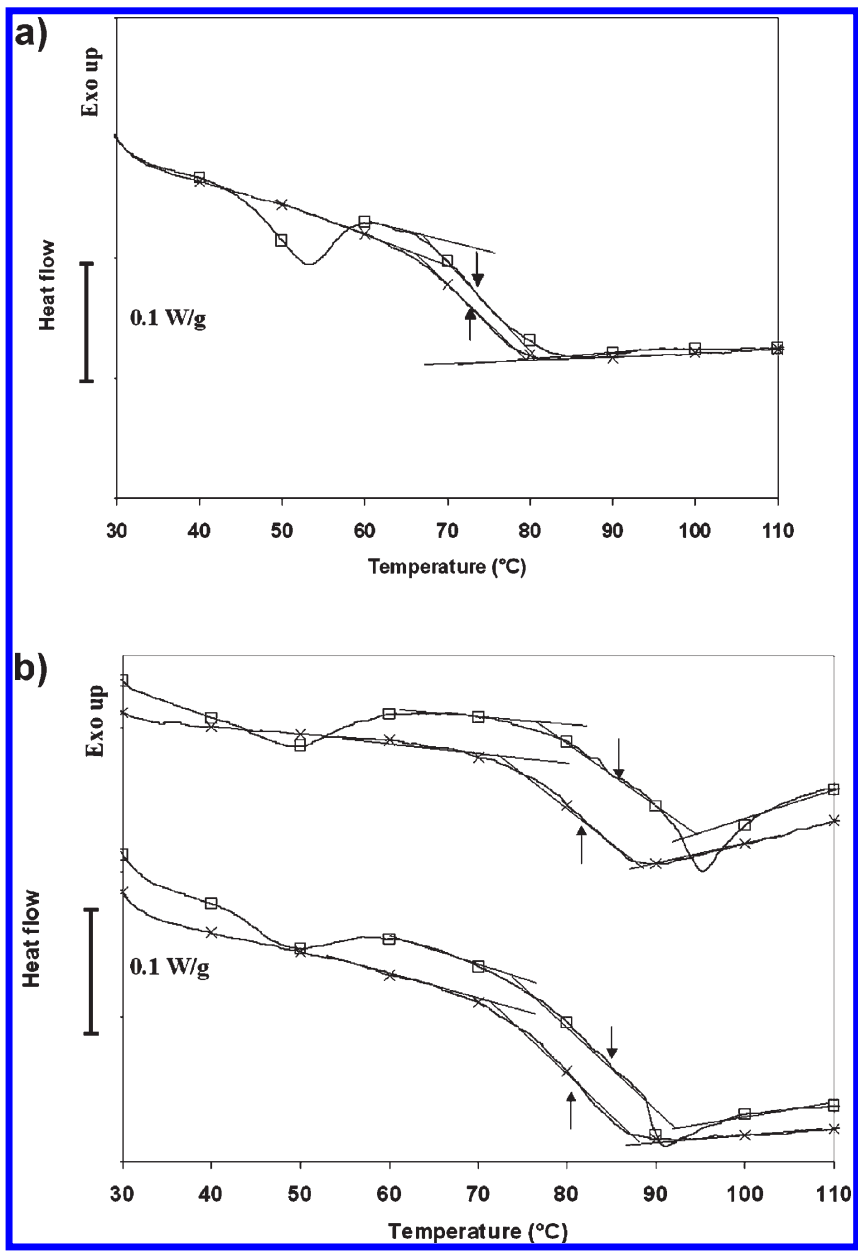

Figure 7. DSC thermogram with two successive scans (1st, $\square$; 2nd, $\times$ ) for the nondeformed sample (a) and the two deformed samples (b) at 90 (top) and $115^{\circ} \mathrm{C}$ (bottom). The arrows indicate the glass transition.

transition temperature determined from the first scan is higher than the one drawn from the second scan at 85 instead of $80^{\circ} \mathrm{C}$. This result confirms the DMTA measurements showing that deformation induces an increase of the glass transition due to a decrease in molecular mobility.

At the end of glass transition, an endothermic peak is observed at 95 and $90{ }^{\circ} \mathrm{C}$ on the first scan for the samples deformed at 90 and $115^{\circ} \mathrm{C}$, respectively. The origin of this event is still poorly known and is currently being studied. It could be due to (i) physical aging of the constrained part of the sample (i.e., stretched segments), (ii) shrinkage of the sample in the DSC pan due to the relaxation of the oriented phase, ${ }^{30,31}$ or (iii) disappearance of a mesophase formed during the drawing process as observed on PLA. ${ }^{32}$

Both DMTA and DSC reveal that the stress induced by the deformation leads to a higher temperature for the maximum of recovery stress, the main mechanical relaxation and the calorimetric glass transition. Thus, optimization of the recovery temperature for starch-based materials could be done by controlling their deformation temperature. The observation of a higher $T_{\mathrm{g}}$ suggests that deformation in the rubbery state induces a decrease of the molecular mobility. No crystallinity is detected, either by DMTA or by WAXS. This makes it possible to conclude that this change in mobility is not affected by crystallinity but by 
the deformation. As proposed by Stoclet et al., ${ }^{32}$ the deformation can produce a mesophase which corresponds to an intermediate state between amorphous and crystalline state and is not detectable by conventional WAXS. This mesophase would be responsible for the decrease of the molecular mobility in stretched specimens. At a temperature close to the deformation temperature, the mesophase disappears and leads to the observable endothermic events in DSC thermograms.

\section{CONCLUSION}

The mechanical behavior of extruded starch is similar to that of amorphous polymers. When the deformation temperature increases, the stress at break decreases while the elongation at break increases.

The multiscale approach used shows that the residual stress, determined by a recovery stress test, is linked to chain orientation. Both decrease linearly when the deformation temperature is increased.

Deformation above the glass transition temperature induces a decrease in mobility. It would be interesting to separately study the effect of residual stress and orientation in order to elucidate the origin of this change in molecular mobility, hypothetically attributed to a secondary network formed during deformation and stabilizing the oriented macromolecules of the stretched shape memory starch material.

\section{AUTHOR INFORMATION}

\section{Corresponding Author}

*Telephone: +33 (0)2 406751 47. Fax: +33 (0)2 40675043. E-mail: denis.lourdin@nantes.inra.fr.

\section{ACKNOWLEDGMENT}

This study was carried out with the support of the French Environment and Energy Management Agency (ADEME), as well as the INRA/CNRS CPDD programs. The authors would like to thank R. Désirest, M. De Carvalho and B. Pontoire (INRA, Nantes) for extrusion, DSC and X-ray diffraction experiments as well as J.M. Chenal (Mateis, INSA Lyon) for helpful discussion.

\section{REFERENCES}

(1) Lendlein, A.; Kelch, S. Angew. Chem. Int. Ed. 2002, 41, 20342057.

(2) Lendlein, A.; Langer, R. Science 2002, 296, 1673-1676.

(3) Otsuka, K.; Wyman, C. M. In Shape memory materials: Cambridge Univ. Press: Cambridge, U.K., 1998; Chapter 9, pp 203-218.

(4) Liu, C.; Qin, H.; Mather, P. T. J. Mater. Chem. 2007, 17 $1543-1558$.

(5) Buléon, A.; Colonna, P.; Planchot, V.; Ball, S. Int. J. Biol. Macromol. 1998, 23, 85-112.

(6) Colonna, P.; Buléon, A. In Starch: characterization, properties and applications, Bertolini, A., Eds.; CRC Press LLC: Boca Raton, FL, 2009; Chapter 4.

(7) DellaValle, G.; Boche, Y.; Colonna, P.; Vergnes, B. Carbohydr. Polym. 1995, 28, 255-264.

(8) Chaunier, L.; Lourdin, D. Starch-Starke 2009, 61, 116-118.

(9) Véchambre, C.; Chaunier, L.; Lourdin, D. Macromol. Mater. Eng. 2010, 295, 115-122.

(10) Willett, J. L. Macromol. Chem. Phvs. 2008, 209, 764-772.

(11) Desevaux, C.; Dubreuil, P.; Lenaerts, V.; Girard, C. J. Biomed. Mater. Res. 2002, 63, 772-779.
(12) Withers, P. J.; Bhadeshia, H. K. D. H. Mater. Sci. Tech. Ser. 2001, $17,355-365$.

(13) Withers, P. J.; Bhadeshia, H. K. D. H. Mater. Sci. Tech. Ser. 2001, $17,366-375$.

(14) Tobushi, H.; Hara, H.; Yamada, E.; Hayashi, S. Smart Mat. Struct. 1996, 5, 483-491.

(15) Véchambre, C.; Buléon, A.; Chaunier, L.; Jamme, F.; Lourdin, D. Macromolecules 2010, 43, 9854-9858.

(16) Therien-Aubin, H.; Gautrot, J. E.; Zhang, J.; Zhu, X. X. Polymer 2010, 51, 22-25.

(17) Wong, Y. S.; Xiong, Y.; Venkatraman, S. S.; Boey, F. Y. C. I. Biomat. Sci-Polvm. E. 2008, 19, 175-191.

(18) Shelby, M. D.; Wilkes, G. L. J. Polym. Sci., Part B: Polym. Phys. 1998, 36, 2111-2128.

(19) Diaz-Calleja, R.; Riandle, E.; Guzman, J. J. Polym. Sci., Part B: Polvm. Phys. 1986, 24, 337-344.

(20) Chanvrier, H.; Colonna, P.; DellaValle, G.; Lourdin, D. Carbohydr. Polym. 2004, 59, 109-119.

(21) Vansoest, J. J. G.; Dewit, D.; Vliegenthart, J. F. G. J. Appl. Polym. Sci. 1996, 61, 1927-1937.

(22) Pick, M.; Lovell, R.; Windle, A. H. Polymer 1980, 21, 1017-1024.

(23) Miller, R. L.; Boyer, R. F.; Heijboer, J. J. Polym. Sci., Part B: Polvm. Phvs. 1984, 22, 2021-2041.

(24) Duchesne, C.; Kong, X.; Brisson, J.; Pézolet, M.; Prud'homme, R. E. Macromolecules 2002, 35, 8768-8773.

(25) Tey, S. J.; Huang, W. M.; Sokolowski, W. M. Smart. Mater. Struct. 2001, 2, 321-325.

(26) Wong, Y. S.; Venkatraman, S. S. Acta Mater. 2010, 58, 49-58.

(27) Matthews, R. G.; Ajji, A.; Dumoulin, M. M.; Prud'homme, R. E. Polvmer 2000, 41, 7139-7145.

(28) Munch, E.; Pelletier, J. M.; Sixou, B.; Vigier, G. Polymer 2006, 47, 3477-3485.

(29) Shogren, R. L. Carbohvdr. Polvm. 1992, 19, 83-90.

(30) Aou, K.; Kang, S.; Hsu, S. L. Macromolecules 2005, 38, $7730-7735$.

(31) Lee, S. C.; Han, J. I.; Jeong, Y. G.; Kwon, M. Macromolecules 2010, 43, 25-28.

(32) Stoclet, G.; Seguela, R.; Lefebvre, J. M.; Rochas, C. Macromolecules 2010, 43, 7228-7237. 